\title{
Verrugas plantares: caminando hacia la adherencia
}

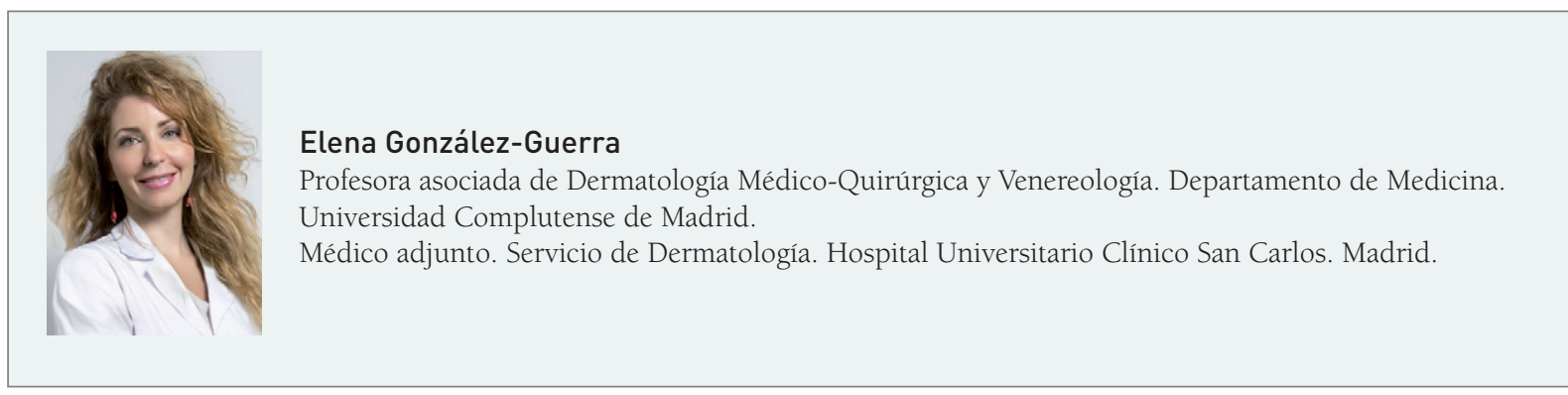

\section{RESUMEN}

Las verrugas son lesiones cutáneas causadas por el virus del papiloma humano. Es esta una infección ubicua y frecuente, que, en numerosas ocasiones, se elimina por la respuesta inmunitaria del hospedador. En otras, persisten y requieren tratamiento para eliminar morbilidad y mejorar la calidad de vida. Las verrugas plantares y las vulgares deben ser tratadas con métodos no agresivos, que no produzcan dolor ni cicatriz. El único tratamiento de primera línea con nivel de evidencia 1+, grado de recomendación A en las guías clínicas — dermatología, pediatría y atención primaria- y aprobado por la Food and Drug Administration (FDA) estadounidense para el tratamiento de las verrugas vulgares y plantares es el ácido salicílico. La aplicación en parches de liberación controlada aumenta la eficacia y, por su comodidad, la adherencia del paciente, quizá el problema más llamativo que dificulta los buenos resultados.

\section{LAS VERRUGAS: ¿QUÉ SON?}

Las verrugas — que no nevos, acrocordones, fibromas, queratosis seborreicas, quistes o cualquier otra excrecencia que asome sobre la piel- son el fruto de una infección vírica —esto es, de una coloniza- ción primero e integración después— de un serotipo del virus del papiloma humano (VPH) en las células epiteliales.

\section{EL VIRUS}

El VPH pertenece al género Papillomavirus de la familia Papillomaviridae. De esta nomenclatura, surge la denominación admisible de «papiloma» que se aplica a las verrugas plantares. Es un virus pequeño y sin envoltura, de cápside icosaédrica de $50 \mathrm{~nm}$, organizada en 72 capsómeros. Cada uno de ellos está constituido por dos proteínas estructurales, L1 y L2, ambas codificadas por el virus, que se unen y estabilizan la cápside mediante puentes disulfuro. Posee un ácido desoxirribonucleico (ADN) bicatenario circular. Se han descrito por ahora más de 100 serotipos diferentes del VPH ${ }^{1}$.

\section{PREVALENCIA}

El VPH, virus ubicuo, puede infectar cualquier zona cutánea y mucosa con mucha frecuencia, constituyendo uno de los motivos de mayor consulta dermatológica. De hecho, se calcula una prevalencia del $12 \%$ de la población general ${ }^{2}$, aumentando esta cifra en los niños y adolescentes hasta el $30 \%$. 


\section{CONTAGIO}

Las verrugas se transmiten tanto por contacto directo o indirecto (fómites, ropas), como por autoinoculación, sobre todo, en caso de rotura epidérmica ${ }^{3}$. Sin embargo, y pese a la creencia vulgar, no se transmiten por la sangre. Este es un virus epidermótropo, que no puede vivir en la sangre.

\section{TIPOS DE VERRUGAS}

Las verrugas se diferencian por el serotipo infeccioso, la morfología clínica y la localización. Así, tenemos verrugas vulgares o comunes que aparecen, preferentemente, en el dorso de las manos y las caras laterales de los dedos; las verrugas filiformes, que son, en realidad, una variedad de verruga vulgar, delgadas y unidas a piel por un estrecho pedículo, como un hilo, que se localizan casi siempre en la cara, sobre todo, en los párpados; las verrugas planas sin apenas elevación, usuales en la cara y el dorso de las manos, y las verrugas genitales o condilomas acuminados.

Cada tipo requiere un tratamiento propio, siendo común, en general, el de las verrugas vulgares y plantares.

No existe ningún tratamiento específico sistémico para el $\mathrm{VPH}^{4}$, por lo que la destrucción física de las células infectadas por el virus (o lograr que el propio sistema inmunitario del paciente haga el trabajo) es el objetivo general.

\section{LA VERRUGA PLANTAR}

El serotipo de VPH que suele infectar la piel de la planta de los pies es el tipo $1 \mathrm{y}$, con menor frecuencia, los tipos 2, 4 y 63. Tras su penetración, produce una infección latente, que dará lugar a la verruga clínica al cabo de 1 a 20 meses. Aparecerá, entonces, una zona de hiperqueratosis, circunscrita, bien delimitada, que recuerda a los callos o tilomas, que también son una hiperqueratosis, pero reactiva al roce o presión, de los que se diferencian, además de en su causa, por su aspecto ${ }^{5}$.

Así, la verruga plantar (y la vulgar) interrumpe el dibujo de los dermatoglifos, los surcos fisiológicos de la piel de las plantas y las palmas, mientras que el callo los sigue manifestando (fig. 1).

Además, en la verruga, bien con un dermatoscopio o a simple vista, se pueden ver múltiples puntos negros, que corresponden a trombosis capilares (fig. 2). A menudo, hay que raspar la hiperqueratosis para visualizar mejor este signo.

La verruga plantar duele cuando se la presiona —sobre todo, con una presión lateral—, mientras que el callo suele doler más con la presión vertical.

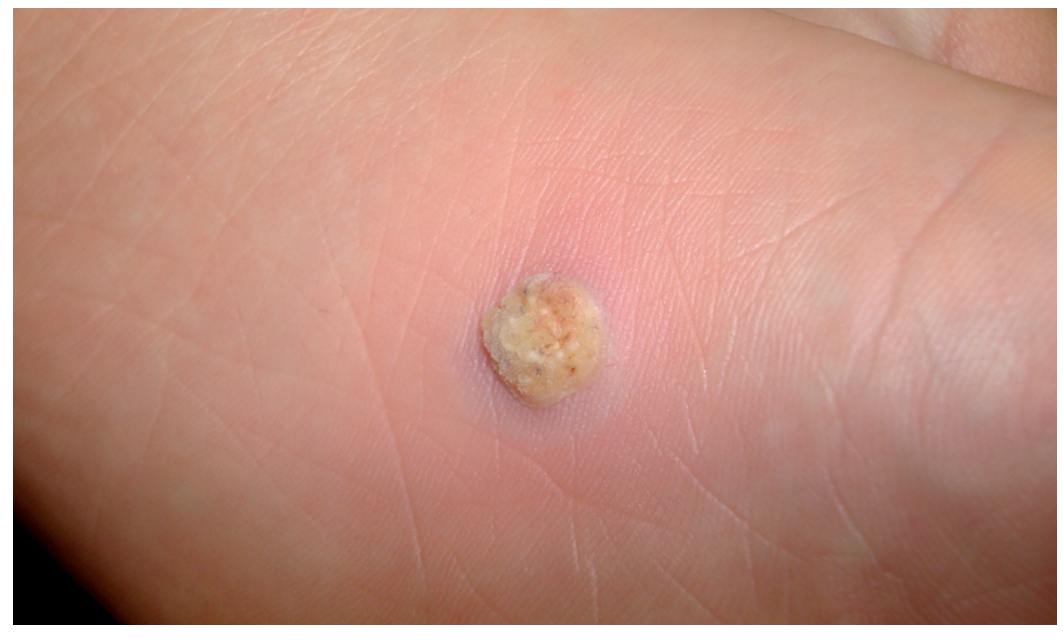

FIGURA 1. Verruga plantar típica. Dermatoglifos interrumpidos por la hiperqueratosis. 


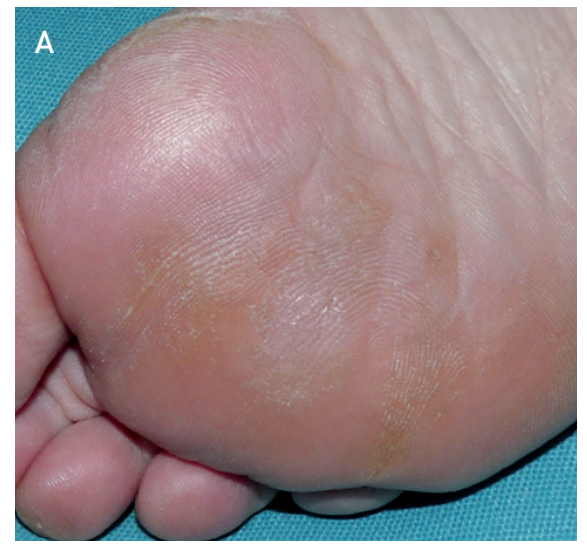

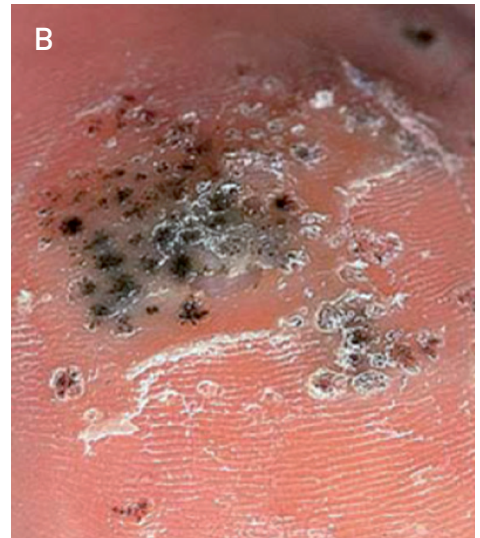

FIGURA 2. A) Hiperqueratosis de un callo, que no interrumpe los dermatoglifos. B) Puntos oscuros correspondientes a capilares trombosados de la verruga plantar, y dermatoglifos interrumpidos.
La verruga plantar puede ser única, llamada también mirmecia, o agruparse en placas superficiales, denominándose, en este caso, verrugas en mosaico. Suele localizarse, entonces, en el talón o sobre la cabeza de los metatarsianos y, generalmente, no duele (fig. 3).

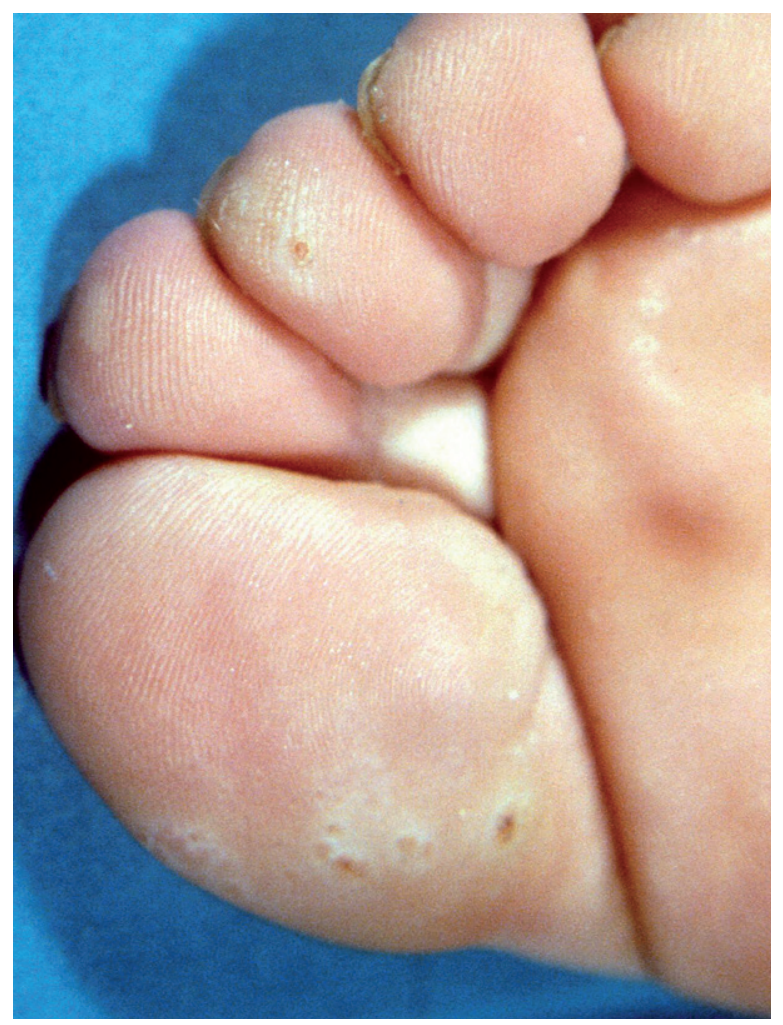

FIGURA 3. Verrugas plantares en mosaico.
El diagnóstico de la verruga plantar es clínico. Si se requiere un estudio histológico, se pueden ver en todo el espesor de la epidermis numerosos gránulos eosinófilos intracitoplasmáticos, que aumentan de tamaño a medida que ascienden a estratos superiores, donde pueden unirse para formar cuerpos de inclusión, de coloración homogénea y morfología irregular. Estos cuerpos de inclusión engloban al núcleo de las células o están separados de él por un halo claro irregular.

El diagnóstico diferencial, únicamente en los casos de larga evolución y clínica atípica, debe hacerse con el carcinoma verrucoso mediante biopsia. Raramente, hay que pensar también en los clavos de la sífilis secundaria, cuando son lesiones múltiples en las palmas y las plantas, junto a otros datos sospechosos.

\section{TRATAMIENTO DE LA VERRUGA PLANTAR}

Es el tratamiento el punto crucial en el manejo de esta dermatosis. Si bien el diagnóstico es fácil en la mayoría de los casos, los tratamientos se hacen difíciles, tanto por la lenta eficacia como por su incumplimiento frecuente. Esto es, existe un problema serio con la adherencia del paciente.

En principio, conviene recordar que no están indicados tratamientos agresivos que sean dolorosos o que dejen cicatrices, tanto por el sufrimiento y 
secuelas como porque la eficacia al $100 \%$ y en todos los casos no existe con ningún tratamiento. Además, independientemente del tratamiento realizado, hay que contar con la posibilidad de recidiva de las verrugas $^{6}$, uniéndose, entonces, la verruga nueva con la cicatriz del tratamiento anterior.

Se desaconsejan, por lo tanto, la exéresis quirúrgica, el láser, la electrocoagulación y otros métodos físicos, más aún si se tiene en cuenta que una buena parte de los casos experimentan una regresión espontánea, coincidiendo con la aparición de anticuerpos fijadores del complemento y el incremento de la inmunidad celular frente a los antígenos del VPH. El 30\% desaparecen en 6 meses, y el $40 \%$, a los 2 años. Pero esta opción puede tardar más —-sobre todo, en inmunodeprimidos y en lesiones de larga evolución-y, mientras existe la verruga plantar, persisten la morbilidad, el dolor, la repercusión estética $^{7-9}$, la mala calidad de vida y el riesgo de contagio. Por ello, la opción que se debe elegir es la de tratar. Y toda esta reflexión es válida igualmente para las verrugas vulgares de otras zonas.

Descartados los tratamientos agresivos dolorosos y que suelen dejar cicatriz, como son los físicos (cirugía, crioterapia, curetaje, electrocoagulación, diatermia, láser de colorante pulsado/ $\mathrm{CO}_{2} \ldots$ ), quedan numerosas posibilidades: tratamientos con productos químicos y cáusticos (queratolíticos, retinoides, formol, glutaraldehído), antimitóticos (bleomicina, podofilotoxina, 5-fluorouracilo, cidofovir), inmunomoduladores (imiquimod, cantaridina, difenciprona) y más ${ }^{10,11}$.

Otros tratamientos curiosos - y esa es toda su bondad-son los remedios populares como la leche de higuera, ajo y sal, y otros «remedios» que no puedo ni quiero mencionar.

\section{ÁCIDO SALICÍLICO}

Valorando los niveles de evidencia científica y la experiencia histórica acumulada, el primero de los tratamientos que elegir para las verrugas plantares, a gran distancia de los restantes, es el tratamiento tópico con ácido salicílico.
Es este el único con el que se ha demostrado eficacia en estudios controlados, convirtiéndose en la terapia de primera línea (nivel de evidencia 1+, grado de recomendación A en las guías clínicas de dermatología, pediatría y atención primaria), siendo también el único aprobado por la Food and Drug Administration (FDA) de los Estados Unidos para el tratamiento de las verrugas vulgares y plantares ${ }^{10,11}$. Se usa en concentraciones entre el 10 y el $40 \%$. Actúa destruyendo lentamente las células epiteliales infectadas y favoreciendo un efecto inmunomodulador local debido a la reacción inflamatoria específica que produce.

El uso tradicional implica una preparación, limando la verruga para disminuir su espesor, y aplicar con posterioridad el ácido salicílico en la concentración deseada y con el excipiente idóneo.

La necesidad de optimizar el tratamiento y aumentar la adherencia - y, por lo tanto, la eficacia y comodidad - ha propiciado la incorporación al arsenal terapéutico de las verrugas plantares y vulgares de una presentación en parches de liberación constante y mantenida durante 8 horas del ácido salicílico, a diferencia del tratamiento tradicional, que vuelca la acción queratolítica de una vez, actuando solamente en el momento en que se aplica. El estudio comparativo multicéntrico de Abou-Auda et al. ${ }^{12}$ ha demostrado un aumento de la eficacia, encontrándose la mejoría e, incluso, la desaparición de la verruga entre 3 y 6 semanas.

\section{BIBLIOGRAFÍA}

1. Grossi Araújo M, Magela Magalhães G, Campos García L, Vieira EC, Ribeiro de Carvalho-Leite ML, Martins Guedes AC. Update on human papillomavirus - Part II: complementary diagnosis, treatment and prophylaxis. An Bras Dermatol. 2021;96(2):12538 .

2. Lynch MD, Cliffe J, Morris-Jones R. Management of cutaneous viral warts. BMJ. 2014;348:g3339

3. Gerlero P, Hernández-Martín A. Actualización sobre el tratamiento de las verrugas vulgares en los niños. Actas Demosifiliogr. 2016; 107(7):551-8

4. Simonart T, De Maertelaer V. Systemic treatments for cutaneous warts: a systematic review. J Dermatolog Treat. 2012;23(1):72-7.

5. Witchey DJ, Witchey NB, Roth-Kauffman MM, Kauffman MK. Plantar warts: epidemiology, pathophysiology, and clinical management. J Am Osteopath Assoc. 2018;118(2):92-105. 
6. Guerra-Tapia A, González-Guerra E. Verrugas vulgares. En: Algoritmos terapéuticos en dermatología básica. Madrid: Editorial Médica Panamericana; 2013. p. 15-35.

7. Soenjoyo KR, Chua BWB, Wee LWY, Koh MJA, Ang SB. Treatment of cutaneous viral warts in children: a review. Dermatol Ther. 2020;33(6):e14034.

8. Sterling JC, Gibbs S, Haque Hussain SS, Mohd Mustapa MF, Handfield-Jones SE. British Association of Dermatologists' guidelines for the management of cutaneous warts 2014. Br J Dermatol. 2014;171(4):696-712.
9. Gibbs S, Harvey I, Sterling J, Stark R. Local treatments for cutaneous warts: systematic review. BMJ. 2002;325(7362):461.

10. Kwok CS, Holland R, Gibbs S. Efficacy of topical treatments for cutaneous warts: a meta-analysis and pooled analysis of randomized controlled trials. Br J Dermatol. 2011;165(2):233-46.

11. Kwok CS, Gibbs S, Bennett C, Holland R, Abbott R. Topical treatments for cutaneous warts. Cochrane Database Syst Rev. 2012;2012(9):CD001781.

12. Abou-Auda H, Soutor C, Neveaux JL. Treatment of verruca infections (warts) with a new transcutaneous controlled release system. Curr Ther Res Clin Exp. 1987;41:552-6. 